\title{
Highly sensitive potentiometric sensor for detection of mercury in $\mathrm{Cl}^{-}$-rich samples
}

\author{
Rongning Liang ${ }^{\mathrm{a}, \mathrm{b}, 1}$, Qianwen Wang ${ }^{\mathrm{c}, 1}$, Wei Qin ${ }^{\mathrm{a}, \mathrm{b}, *}$ \\ a Key Laboratory of Coastal Environmental Processes and Ecological Remediation, Yantai Institute of Coastal Zone Research (YIC), \\ Chinese Academy of Sciences (CAS), Yantai, Shandong 264003, PR China \\ b Shandong Provincial Key Laboratory of Coastal Environmental Processes, YICCAS, Yantai, Shandong 264003, PR China \\ c Central Laboratory, Qingdao Agricultural University, Qingdao, Shandong 266109, PR China
}

\section{A R T I C L E I N F O}

\section{Article history:}

Received 4 June 2014

Received in revised form 20 October 2014

Accepted 8 November 2014

Available online 15 November 2014

\section{Keywords:}

Potentiometry

Ion-selective electrodes

Asymmetric membranes

Anionic mercury species

$\mathrm{Cl}^{-}$-rich samples

\begin{abstract}
A B S T R A C T
Potentiometric sensors have been exploited for the determination of $\mathrm{Hg}^{2+}$ ions. However, applications

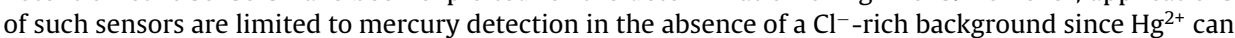
readily form coordination complexes with $\mathrm{Cl}^{-}$. This paper describes a potentiometric sensor for the determination of anionic mercury species using tert-butylcalix[4]arene-tetrakis(N,N-dimethylthioacetamide) as anion-selective ionophore and tridodecylmethylammonium chloride as ion exchanger. An asymmetric membrane rotating ion-selective electrode configuration is used to improve the detection sensitivity. By using $\mathrm{HgCl}_{3}{ }^{-}$as a model of anionic mercury species, the proposed method allows potentiometric detection of mercury down to nanomolar levels in samples containing $0.05 \mathrm{M} \mathrm{NaCl}$ background electrolyte. The practical application of the proposed sensor has been performed for the determination of total mercury concentrations in diluted seawater samples.
\end{abstract}

(c) 2014 Elsevier B.V. All rights reserved.

\section{Introduction}

Mercury pollution is increasingly becoming a serious environmental problem throughout the world since mercury tends to accumulate in food chains and can cause cell death, brain damage and birth defects [1]. Therefore, routine detection of mercury is vital for environmental monitoring and assessment. Currently available detection methods for mercury include cold vapor atomic absorption spectrometry [2,3], atomic fluorescence spectrometry [4,5], and inductively coupled plasma mass spectrometry [6]. Although these approaches are well established, they require expensive apparatus and complicated sample pretreatment [7,8].

As generic and highly successful electrochemical sensors, ion-selective electrodes (ISEs) have shown to be promising for environmental trace analysis and potentiometric biosensing [9-11]. Today ISEs routinely offer detection limits in the nanomolar or lower concentration range without any accumulation step [12-18].

\footnotetext{
* Corresponding author at: Key Laboratory of Coastal Environmental Processes and Ecological Remediation, Yantai Institute of Coastal Zone Research (YIC), Chinese Academy of Sciences (CAS), Yantai, Shandong 264003, PR China.

Tel.: +86535 2109156; fax: +865352109000.

E-mail address: wqin@yic.ac.cn (W. Qin).

1 These authors contributed equally to this work.
}

A few ISEs have been reported for the determination of trace-level mercury ions, specially divalent mercury ions (i.e., $\mathrm{Hg}^{2+}$ ) [19-22]. Unfortunately, the present $\mathrm{Hg}^{2+}$-ISEs are not practically useful in $\mathrm{Cl}^{-}$-rich media such as seawater samples where mercury mainly exists in the forms of anionic species such as $\mathrm{HgCl}_{4}{ }^{2-}$ and $\mathrm{HgCl}_{3}{ }^{-}$ owing to the favorable complexation of $\mathrm{Hg}^{2+}$ with $\mathrm{Cl}^{-}$[23]. Very few ISEs have been reported for the determination of anionic mercury ions. Kim et al. reported a novel ISE based on neutral carrier for potentiometric detection of mercury anions in $\mathrm{Cl}^{-}$-rich media [24]. However, the detection limit of the method for detection of mercury anionic species in $0.05 \mathrm{M} \mathrm{NaCl}$ is around the micromolar range. This poses serious limit to its use at trace levels as required for determining mercury in environmental samples. Thus, the development of a highly sensitive potentiometric sensor for mercury in $\mathrm{Cl}^{-}$-rich environmental samples still remains a challenge.

Herein, we present a novel and highly sensitive potentiometric sensor for detection of mercury species in $\mathrm{Cl}^{-}$-rich samples. The proposed anion-selective membrane electrode is fabricated by using the neutral carrier tert-butylcalix[4]arene-tetrakis(N,Ndimethylthioacetamide) (lead ionophore IV) as the chloro-mercury anion-selective ionophore and tridodecylmethylammonium chloride (TDMACl) as the anion exchanger. Potentiometric detection of mercury is performed in the presence of $0.05 \mathrm{M} \mathrm{NaCl}$ background which ensures the anionic forms of mercury species. To improve the detection sensitivity of the potentiometric sensor, 
the asymmetric membrane rotating ISE configuration based on the nonequilibrium steady-state diffusion process of primary ions at the sample-membrane interface is used [25,26]. By choosing $\mathrm{HgCl}_{3}{ }^{-}$as a model, the proposed method shows a low detection limit of $4.5 \times 10^{-10} \mathrm{~mol} / \mathrm{L}$ in the presence of $0.05 \mathrm{M} \mathrm{NaCl}$. This sensing strategy can offer promising potential for potentiometric detection of mercury species at trace levels in $\mathrm{Cl}^{-}$-rich media such as seawater and biological samples.

\section{Experimental}

\subsection{Reagents and materials}

High molecular weight poly (vinyl chloride) (PVC), 2nitrophenyl octyl ether (o-NPOE), TDMACl, the lipophilic salt tetradodecylammonium tetrakis(4-chlorophenyl)borate (ETH $500)$, lead ionophore IV and the $\mathrm{H}^{+}$ionophore 5-(octadecanoyloxy)2-(4-nitrophenylazo) phenol (ETH 2412) were purchased from Fluka AG (Buchs, Switzerland). $\mathrm{NaCl}$ was Suprapure from Sigma-Aldrich. The certified reference material of seawater sample (GBW(E) 080042) was provided by the Second Institute of Oceanology, China. Aqueous solutions were prepared with freshly deionized water ( $18.2 \mathrm{M} \Omega \mathrm{cm}$ specific resistance) obtained with a Pall Cascada laboratory water system. A stock solution was prepared by dissolving $\mathrm{HgCl}_{2}$ in $0.05 \mathrm{M} \mathrm{NaCl}$ and then diluted to various concentrations of working solutions with $0.05 \mathrm{M} \mathrm{NaCl}$. Tetrahydrofuran (THF) was freshly distilled prior to use. All other reagents were analytical grade and used without any further purification.

\subsection{Preparation of ISE membranes and electrodes}

The traditional homogeneous $\mathrm{HgCl}_{3}{ }^{-}$-ISE membranes contained (in wt\%) lead iononphore IV (1), TDMACl (1), o-NPOE (65), and PVC (33). The components of each membrane (totaling $360 \mathrm{mg}$ ) were dissolved in THF ( $2.5 \mathrm{~mL}$ ) and poured into a glass ring (i.d. $36 \mathrm{~mm}$ ) fixed on a glass support to obtain a transparent membrane of $\sim 200$ $\mu \mathrm{m}$ thickness. After overnight evaporation of the solvent, $8-\mathrm{mm}$ diameter disks were punched from the mother membranes and glued to a plasticized PVC tubing with THF/PVC slurry. The asymmetric membranes were prepared by evenly spreading $5 \mu \mathrm{L}$ of a TDMACl solution $(0.7 \mathrm{mg} / \mathrm{mL}$ in THF) on the surface ( 8 - $\mathrm{mm}$ diameter) of the membrane matrix containing (in wt\%) lead ionophore IV (1), ETH 2412 (0.5), ETH 500 (1), o-NPOE (27.5), and PVC (70) and letting the active layer dry for $1 \mathrm{~h}$. For mercury detection, $0.05 \mathrm{M}$ $\mathrm{NaCl}$ and $0.05 \mathrm{M} \mathrm{NaCl}$ solution added with $4.4 \mu \mathrm{M} \mathrm{HgCl}_{2}$ were used as the inner filling solutions for the asymmetric and conventional homogeneous membrane based ISEs, respectively. For evaluation of the selectivity coefficients, $0.01 \mathrm{M} \mathrm{NaCl}$ was used as the inner filling solution for both electrodes. All the electrodes were conditioned in a solution identical to the inner filling solution for 1 day.

\subsection{EMF measurements}

A rotating silver disk electrode (ATA-1B, Jiangsu Jiangfen Electroanalytical Instrument Co., Ltd., China) with a diameter of $3 \mathrm{~mm}$ was used as internal reference electrode as described before [25]. The plasticized PVC tubing with the asymmetric ISE membrane glued at the distal end was filled with the internal filling solution of $0.05 \mathrm{M} \mathrm{NaCl}$ and then screwed onto the silver disk electrode. All experiments were performed with a rotating (at $3000 \mathrm{rpm}$ ) or stirring mode configuration (using a stir bar operating at $200 \mathrm{rpm}$ ). Electromotive force (EMF) values were measured at $20-21^{\circ} \mathrm{C}$ using a PXSJ-216 pH meter (Shanghai, China) in the galvanic cell: saturated calomel electrode (SCE) $0.1 \mathrm{M} \mathrm{LiOAc/sample}$ solution/ISE membrane/inner filling solution/AgCl/Ag.

Potentiometric selectivity coefficients were determined by the separate solution method (see the Supporting information for details) [27]. The EMF values were corrected for the liquidjunction potentials with the Henderson equation. The ion activity coefficients were calculated according to the Debye-Hückel equation [28].

\subsection{Reproducibility procedure}

After each measurement, the asymmetric membrane based $\mathrm{HgCl}_{3}{ }^{-}$-selective electrode was washed with deionized water for $30 \mathrm{~s}$ and then with $50 \mathrm{mM} \mathrm{NaHCO} / \mathrm{Na}_{2} \mathrm{CO}_{3}$ buffer solution of $\mathrm{pH}$ 10.0 for 10 min to strip $\mathrm{HgCl}_{3}{ }^{-}$out of the sensing membrane. The electrode was reconditioned in $20 \mathrm{mM}$ citric acid/ $/ \mathrm{Na}_{2} \mathrm{HPO}_{4}$ buffer solution of $\mathrm{pH} 7.4$ containing $0.05 \mathrm{M} \mathrm{NaCl}$ for $10 \mathrm{~min}$ to restore the membrane.

\section{Results and discussion}

It has been well established that $\mathrm{Hg}$ (II) ions can complex with chloride ions and form $\mathrm{HgCl}^{+}, \mathrm{HgCl}_{2}, \mathrm{HgCl}_{3}{ }^{-}$and $\mathrm{HgCl}_{4}{ }^{2-}$ as described below [23,24,29]:

$$
\begin{aligned}
& \mathrm{Hg}^{2+}+\mathrm{Cl}^{-} \leftrightharpoons \mathrm{HgCl}^{+} \quad \operatorname{lgK}(298.15 \mathrm{~K})=7.3 \\
& \mathrm{HgCl}^{+}+\mathrm{Cl}^{-} \leftrightharpoons \mathrm{HgCl}_{2} \quad \operatorname{lgK}_{2}(298.15 \mathrm{~K})=6.3 \\
& \mathrm{HgCl}_{2}+\mathrm{Cl}^{-} \leftrightharpoons \mathrm{HgCl}_{3}{ }^{-} \quad \operatorname{lgK}(298.15 \mathrm{~K})=0.9 \\
& \mathrm{HgCl}_{3}{ }^{-}+\mathrm{Cl}^{-} \leftrightharpoons \mathrm{HgCl}_{4}{ }^{2-} \quad \operatorname{lgK}_{4}(298.15 \mathrm{~K})=0.6
\end{aligned}
$$

According to the above equations, it can be calculated that in $\mathrm{Cl}^{-}$-rich samples such as seawater samples with a typical chloride ion concentration of about $0.5 \mathrm{M}$, the dominant species is the negatively charged mercury chloride complex $\mathrm{HgCl}_{4}{ }^{2-}$ which constitutes about $78.7 \%$ of the total mercury species. The anionic and neutral chloro-mercury complexes $\mathrm{HgCl}_{3}{ }^{-}$and $\mathrm{HgCl}_{2}$ constitute 17.9 and 3.0\%, respectively. However, it should be noted that almost all of the previously developed ISEs used for mercury are limited to the detection of positively charged $\mathrm{Hg}^{2+}$ ions. There is only one potentiometric sensor reported by Kim et al. for the determination of anionic chloro-mercury complexes. However, the sensor cannot be utilized in practical mercury detection owing to its limited sensitivity [24]. In this work, we explored a highly sensitive potentiometric sensor for the determination of chloro-mercury anions. Lead ionophore IV was used as the ionophore for selective recognition of chloro-mercury complexes. By employing the asymmetric membrane based ISE configuration previously reported by our group $[25,26]$, potentiometric detection of trace-level mercury in $\mathrm{Cl}^{-}$-rich samples can be achieved.

\subsection{Feasibility of the proposed approach}

Selective interaction between a given analyte anion and a lipophilic carrier within the membrane is essential for the development of anion-sensitive polymeric membranes that exhibit non-Hofmeister potentiometric selectivity patterns [30]. In order to achieve selective and sensitive potentiometric detection of anionic mercury chloride complexes, ion carriers that selectively recognize these complexes are required. It has been well known that ionophores containing sulfur and nitrogen donor atoms coordinate selectively with heavy metal ions such as $\mathrm{Hg}^{2+}, \mathrm{Ag}^{+}$and $\mathrm{Pb}^{2+}$. Nevertheless, it is still unknown that whether or not these ionophores can form strong complexes with metal chloride complexes such as $\mathrm{HgCl}_{3}{ }^{-}$and $\mathrm{AgCl}_{2}{ }^{-}$. In this work, lead ionophore IV which was usually employed as the $\mathrm{Pb}^{2+}$-selective ionophore was used as the 


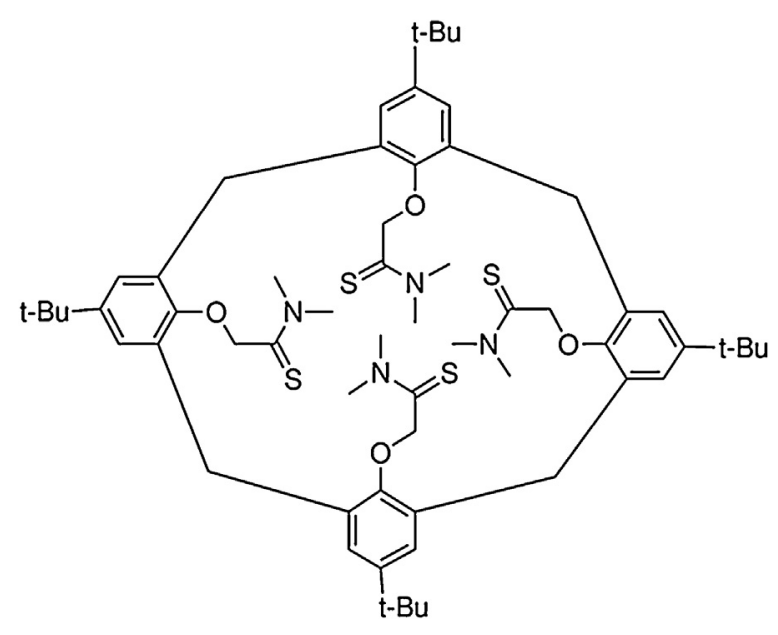

Scheme 1. Chemical structure of lead ionophore IV.

ion carrier for chloro-mercury anionic complexes for the first time. The chemical structure of lead ionophore IV is shown in Scheme 1. Since lead ionophore IV contains four sulfur atoms which are excellent coordinating sites for mercury atoms, it can be expected that the ligand will form strong coordination interactions with the mercury atom center in the chloro-mercury anionic complexes [31,32]. Additionally, it should be noted that the chloride concentration influences the $\mathrm{Hg}$ speciation. In $0.05 \mathrm{M} \mathrm{NaCl}$, the dominant species are $\mathrm{HgCl}_{2}, \mathrm{HgCl}_{3}{ }^{-}$and $\mathrm{HgCl}_{4}{ }^{2-}$ with a distribution of $66.7 \%, 27.7 \%$ and $5.6 \%$, respectively [24]. In this case, we assume that $\mathrm{HgCl}_{3}-$ is dominately responsible for the observed anionic response of the proposed sensor. Consequently, $\mathrm{HgCl}_{3}{ }^{-}$is used as the representative anion for the chloro-mercury anionic complexes in all further experiments. The sensing mechanism of the proposed ionophore and the schematic representation of the coordination between the ionophore and $\mathrm{HgCl}_{3}{ }^{-}$are shown in Scheme S1 in the Supporting information. In order to decrease the membrane resistance, reduce cation interference and improve selectivity of the proposed sensor, the anion exchanger TDMACl was incorporated into the sensing membrane.

\subsection{Influence of the ion carrier}

To illustrate whether conventional neutral ionophores for metal cations can bind strongly and selectively to anionic metal chloride complexes, potentiometric anion selectivity coefficients of the ionophore-free and neutral ionophore incorporated membranes were compared. The selectivity coefficients of the proposed membranes were evaluated by using Bakker' method to eliminate the influence of the inherent sensitivity limit on the ISE response toward interfering ions [27]. The logarithmic Nikolskii coefficients

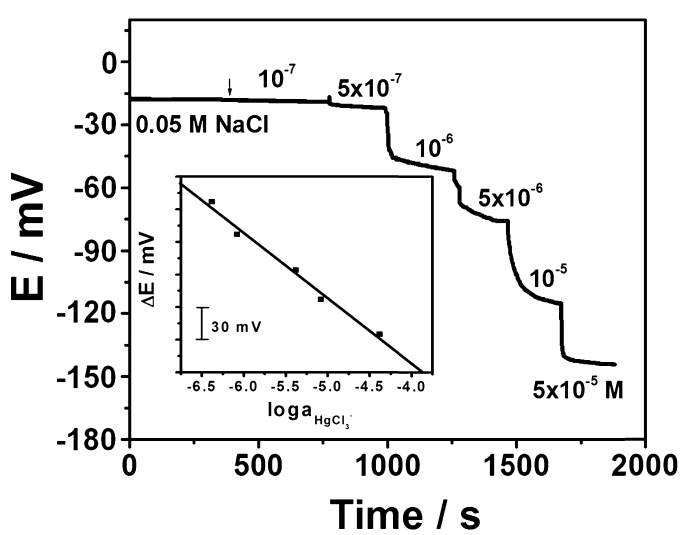

Fig. 1. Time-dependent EMF response traces of the traditional homogeneous membrane based ISE conditioned with the primary ions for measuring $\mathrm{HgCl}_{3}-$ in $0.05 \mathrm{M}$ $\mathrm{NaCl}$ under constant stirring. The inset shows the corresponding calibration curve. Homogeneous membrane ingredients: $1 \mathrm{wt} \%$ lead iononphore IV, $1 \mathrm{wt} \% \mathrm{TDMACl}$, $65 \mathrm{wt} \% \mathrm{o}-\mathrm{NPOE}$ and $33 \mathrm{wt} \%$ PVC. The inner filling solution of the proposed electrode was $0.05 \mathrm{M} \mathrm{NaCl}$ solution added with $4.4 \mu \mathrm{M} \mathrm{HgCl}_{2}$.

for $\mathrm{HgCl}_{3}{ }^{-}\left(\log K_{\mathrm{HgCl}_{3}^{-}, \mathrm{Y}}^{\mathrm{pot}}\right)$ over other anions are summarized in Table 1. It is clear that the anion-selective membrane using lead ionophore IV as an anion carrier and TDMACl as ion exchanger shows excellent selectivity to $\mathrm{HgCl}_{3}{ }^{-}$over other anions such as $\mathrm{Cl}^{-}, \mathrm{SO}_{4}{ }^{2-}, \mathrm{SeO}_{4}{ }^{2-}$ and $\mathrm{MoO}_{4}{ }^{2-}$. The high discrimination against these anions allows $\mathrm{HgCl}_{3}{ }^{-}$ISE to be used in the presence of a high interfering background. Notably, the obtained selectivity coefficients of the ionophore-based membrane electrode over all potential interfering anions are superior to those of the ionophorefree anion-exchanger-based electrode. Of particular significance is the fact that selectivity over chloride is enhanced nearly 1000 -fold. The marked enhancement in chloride selectivity can allow tracelevel potentiometric analysis of mercury in $\mathrm{Cl}^{-}$-rich background such as marine and biological environments. These results indicate that $\mathrm{HgCl}_{3}-$ can preferentially interact with lead ionophore IV within the polymeric membrane phase of the electrode. Also, this observation suggests the possibility that lead ionophore IV serves as an ionophore for the anionic mercury species.

\subsection{Potentiometric responses of the homogeneous membrane to $\mathrm{HgCl}_{3}{ }^{-}$}

The homogeneous membrane containing $1 \mathrm{wt} \%$ lead ionophore IV and $1 \mathrm{wt} \% \mathrm{TDMACl}$ was used for detection of $\mathrm{HgCl}_{3}{ }^{-}$. Fig. 1 shows the potential response of the homogeneous membrane based on lead ionophore IV to $\mathrm{HgCl}_{3}{ }^{-}$in $0.05 \mathrm{M} \mathrm{NaCl}$. As expected, the ISE formulation appears to be effective for the measurement of $\mathrm{HgCl}_{3}{ }^{-}$. The proposed electrode based on the ionophore-doped membrane conditioned by the primary ions (i.e., $\mathrm{HgCl}_{3}{ }^{-}$) shows a

Table 1

Selectivity coefficients of traditional homogeneous membranes with and without lead ionophore IV.

\begin{tabular}{|c|c|c|c|c|c|}
\hline \multirow[t]{2}{*}{ Y } & \multicolumn{2}{|l|}{$\log K_{\mathrm{HgCl}_{3}^{-}, \mathrm{Y}}^{\mathrm{pot}}$} & \multirow[t]{2}{*}{$\mathrm{Y}$} & \multicolumn{2}{|l|}{$\log K_{\mathrm{HgCl}_{3}^{-}, \mathrm{Y}}^{\mathrm{pot}}$} \\
\hline & Without ionophore ${ }^{\mathrm{b}}$ & With ionophore ${ }^{\mathrm{b}}$ & & Without ionophore ${ }^{\mathrm{b}}$ & With ionophore ${ }^{b}$ \\
\hline $\mathrm{Cl}^{-}$ & -5.8 & -8.6 & $\mathrm{SeO}_{4}{ }^{2-}$ & -9.3 & -11.4 \\
\hline $\mathrm{SO}_{4}{ }^{2-}$ & -8.9 & -11.1 & $\mathrm{CrO}_{4}^{2-}$ & -6.9 & -9.5 \\
\hline $\mathrm{NO}_{3}^{-}$ & -2.8 & -5.1 & $\mathrm{WO}_{4}{ }^{2-}$ & -8.5 & -9.6 \\
\hline $\mathrm{OH}^{-}$ & -6.1 & -8.2 & $\mathrm{MoO}_{4}{ }^{2-}$ & -9.5 & -11.2 \\
\hline $\mathrm{SCN}^{-}$ & -2.5 & -4.3 & $\mathrm{MnO}_{4}^{-}$ & 0.9 & -1.3 \\
\hline $\mathrm{ClO}_{4}^{-}$ & -1.7 & -3.1 & $\mathrm{AgCl}_{2}^{-}$ & 0.6 & -1.8 \\
\hline
\end{tabular}

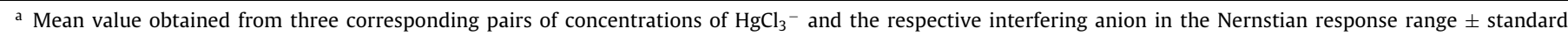
deviation.

b Membrane with 1 wt\% TDMACl. 

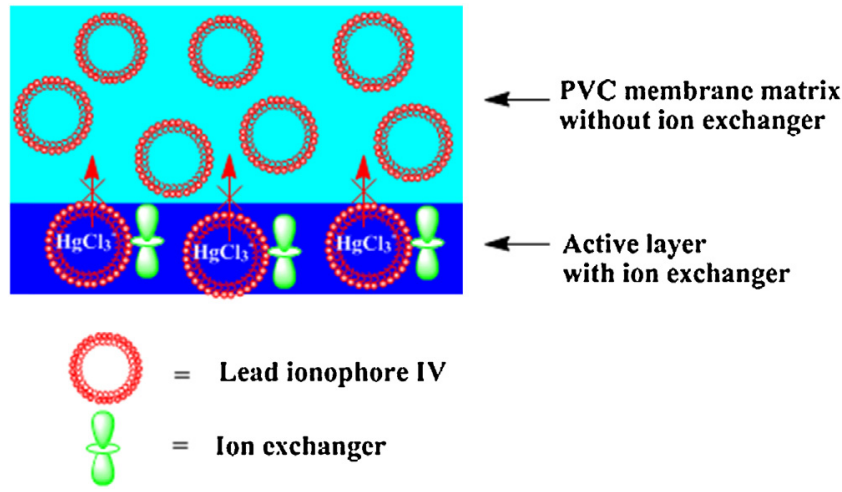

Scheme 2. Representation of the asymmetric ISE membrane for the determination of $\mathrm{HgCl}_{3}{ }^{-}$.

sub-Nernstian response of $48.7 \mathrm{mV} /$ decade over the concentration range of $5.0 \times 10^{-7}$ to $5.0 \times 10^{-5} \mathrm{~mol} / \mathrm{L}$, which is more than 1 order of magnitude lower than that reported by Kim et al. [24]. It should be noted that the response behavior of the electrode with a slope of $48.7 \mathrm{mV} /$ decade slightly deviates from the Nernstian response. This deviation can be ascribed to the contribution of the divalent $\mathrm{HgCl}_{4}{ }^{2-}$ ions in the test solution.

As shown above, the proposed anion-selective electrode based on the homogeneous membrane can be effectively used for the determination of $\mathrm{HgCl}_{3}{ }^{-}$. However, according to the US Environmental Protection Agency (EPA) standard, the MAL (maximum allowable level) of $\mathrm{Hg}^{2+}$ ions in drinking water is $10 \mathrm{nM}$ [33]. Thus, the obtained detection limit cannot satisfy the requirement for trace-level analysis of mercury in aqueous environmental samples. Based on the selectivity for $\mathrm{HgCl}_{3}{ }^{-}$over $\mathrm{Cl}^{-}$, the expected lower detection limit may be $\sim 10^{-10} \mathrm{M} \mathrm{HgCl}_{3}{ }^{-}$in the presence of $0.05 \mathrm{M}$ $\mathrm{NaCl}$. This is much lower than the value obtained with the homogeneous membrane based electrode. The poor detection limit is probably due to the leaching of $\mathrm{HgCl}_{3}{ }^{-}$from the ISE membrane into the measuring solution [34-38].

\subsection{Asymmetric membrane rotating ISE configuration for sensitive detection of $\mathrm{HgCl}_{3}$}

In our previous reports, it has been well established that an asymmetric membrane rotating ISE configuration can be utilized to significantly improve the detection sensitivity of potentiometric measurements with a high-interfering background [25,26]. The response mechanism of the proposed ISE sensing mode is based on the nonequilibrium steady-state diffusion process of primary ions at the sample-membrane interface. Such nonequilibrium mechanism has been successfully applied to sensitive detection of polyions and lipophilic anions such as perchlorate and periodate $[39,40]$. By promoting the accumulation of primary ions in the boundary layer of the ISE membrane phase by using the asymmetric membrane with high PVC content and rotating the membrane electrode, the nonequilibrium potential response can be largely enhanced and thus the detection sensitivity is improved.

In this work, we extend the application of the asymmetric membrane rotating ISE configuration to the detection of anionic mercury chloride complexes. The asymmetric membrane was formed by evenly spreading the TDMACl solution onto the surface of PVC membrane matrix as described before [25]. In order to eliminate the ion exchange of primary ions in the membrane phase by interfering ions in the sample solution, the proposed electrode is conditioned only with interfering ions (e.g., $0.05 \mathrm{M} \mathrm{NaCl}$ ) before measurements. The lipophilic salt ETH 500 was added to lower the resistance of the PVC membrane matrix. The illustration of asymmetric ISE membrane for the determination of $\mathrm{HgCl}_{3}-$ is shown in

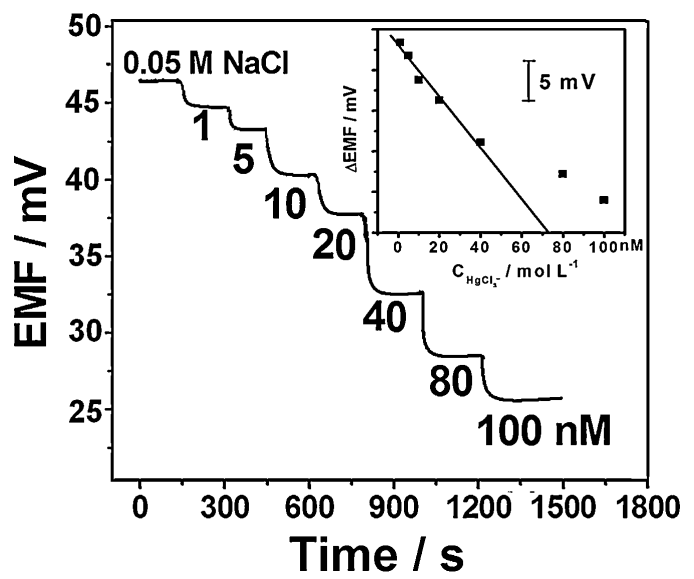

Fig. 2. Potential traces for the asymmetric membrane rotating ISE for measuring $\mathrm{HgCl}_{3}{ }^{-}$in $0.05 \mathrm{M} \mathrm{NaCl}$. The inset shows the calibration curve for $\mathrm{HgCl}_{3}{ }^{-}$detection. The asymmetric membranes were prepared by evenly spreading $5 \mu \mathrm{L}$ of a TDMACl solution $(0.7 \mathrm{mg} / \mathrm{mL}$ in THF) on the surface $(8-\mathrm{mm}$ diameter) of the membrane matrix containing (in wt\%) lead ionophore IV (1), ETH 2412 (0.5), ETH 500 (1), o$\mathrm{NPOE}$ (27.5), and PVC (70). $0.05 \mathrm{M} \mathrm{NaCl}$ was used as the internal filling solution. The rotation speed was $3000 \mathrm{rpm}$.

Scheme 2. As established in our previous work, the detection limit can be improved by suppressing the transmembrane ion fluxes of $\mathrm{HgCl}_{3}{ }^{-}$that have a decisive influence on the potential response. The potential response with the asymmetric membrane is shown in Fig. 2. As expected, the $\mathrm{HgCl}_{3}{ }^{-}$-selective electrode based on the asymmetric membrane exhibits a significantly improved performance. Detailed analysis of the experimental results reveals that there is a linear dependence of the EMF change on the concentration of $\mathrm{HgCl}_{3}{ }^{-}$in the range of $1.0-40 \mathrm{nM}(E=-2.04-0.31 C$, $r=0.988$, with $E$ given in $\mathrm{mV}$ and $C$ in $\mathrm{nM}$ ) with a lower detection of $4.5 \times 10^{-10} \mathrm{~mol} / \mathrm{L}(3 \sigma)$. This detection limit is more than two orders of magnitude lower than that reported by other researchers [24]. Above all, the proposed approach yields a detection limit much below the EPA defined limit (i.e., $10 \mathrm{nM}$ ) in drinking water.

\subsection{Interference study}

The selectivity of the proposed asymmetric membrane was also characterized by using Bakker' method. The selectivity coefficients for $\mathrm{HgCl}_{3}{ }^{-}$over a series of relevant interfering anions are shown in Table 2. As can be seen, the proposed electrode based on asymmetric membrane shows an excellent selectivity to $\mathrm{HgCl}_{3}{ }^{-}$over other anions such as $\mathrm{Cl}^{-}, \mathrm{SO}_{4}{ }^{2-}$ and $\mathrm{NO}_{3}{ }^{-}$, which is also consistent with that obtained by the homogeneous membrane with lead ionophore IV (Table 1). The high sensitivity and excellent selectivity of the proposed asymmetric membrane configuration offer great potential for trace-level potentiometric detection of $\mathrm{HgCl}_{3}{ }^{-}$in the presence of a high electrolyte background, especially for seawater and biological fluid samples.

Table 2

Potentiometric selectivity coefficients, $\log \mathrm{K}_{\mathrm{HgCl}_{3}^{-}, \mathrm{Y}}^{\mathrm{pot}}$, obtained with the separate solution method for the proposed asymmetric membrane based ISE.

\begin{tabular}{lcll}
\hline $\mathrm{Y}$ & $\log K_{\mathrm{HgCl}_{3}^{-}, \mathrm{Y}}^{\mathrm{pot}}$ & $\mathrm{Y}$ & $\log K_{\mathrm{HgCl}_{3}^{-}, \mathrm{Y}}^{\mathrm{pot}}$ \\
\hline $\mathrm{Cl}^{-}$ & -8.7 & $\mathrm{SeO}_{4}{ }^{2-}$ & -10.8 \\
$\mathrm{SO}_{4}{ }^{2-}$ & -10.9 & $\mathrm{CrO}_{4}{ }^{2-}$ & -10.1 \\
$\mathrm{NO}_{3}{ }^{-}$ & -4.7 & $\mathrm{WO}_{4}{ }^{2-}$ & -10.1 \\
$\mathrm{OH}^{-}$ & -8.1 & $\mathrm{MoO}_{4}{ }^{-}$ & -10.5 \\
$\mathrm{SCN}^{-}$ & -3.8 & $\mathrm{MnO}_{4}{ }^{-2}$ & -1.7 \\
$\mathrm{ClO}_{4}{ }^{-}$ & -2.6 & $\mathrm{AgCl}_{2}$ & -1.4 \\
\hline
\end{tabular}

a Mean value obtained from three corresponding pairs of concentrations of $\mathrm{HgCl}_{3}$ and the respective interfering anion in the Nernstian response range \pm standard deviation. 


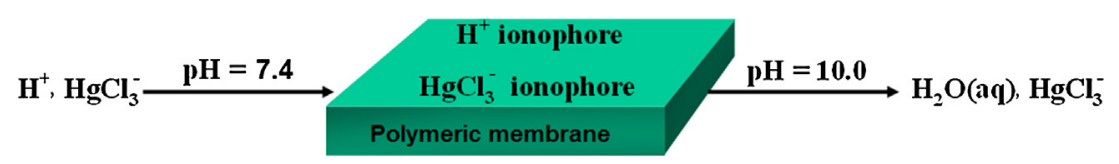

Scheme 3. Illustration of the membrane renewal process.

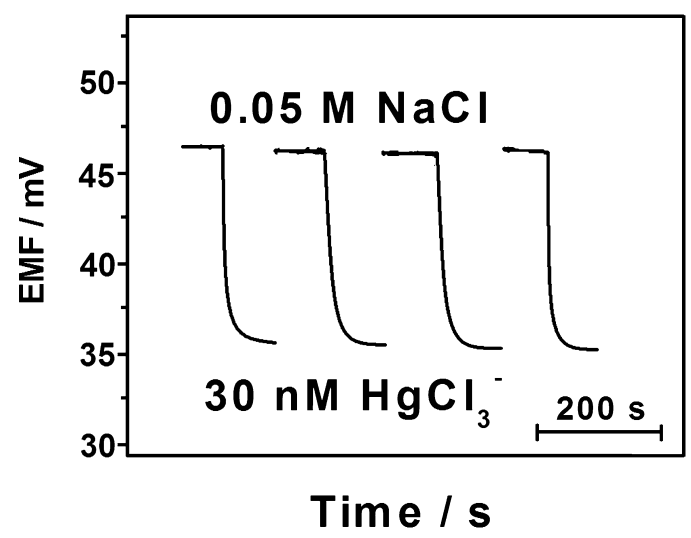

Fig. 3. Reversibility of the proposed asymmetric membrane based ISE for detection of $\mathrm{HgCl}_{3}-$ in $0.05 \mathrm{M} \mathrm{NaCl}$. The concentration of $\mathrm{HgCl}_{3}-$ was $3 \times 10^{-8} \mathrm{M}$. After each measurement, a 10 min stripping with $50 \mathrm{mM} \mathrm{NaHCO} / \mathrm{Na}_{2} \mathrm{CO}_{3}$ buffer solution of pH 10.0 was employed. The other conditions are as given in Fig. 2.

\subsection{Reversibility}

The regeneration process of the proposed electrode is similar to that of the heparin sensor described earlier [41]. The schematic representation of the regeneration process is shown in Scheme 3. The electrically charged $\mathrm{H}^{+}$ionophore ETH 2412 is incorporated as an additional ionophore into the $\mathrm{HgCl}_{3}{ }^{-}$-sensing membrane. This membrane will respond to $\mathrm{pH}$ only at low $\mathrm{H}^{+}$concentrations (e.g., $\mathrm{pH}$ 10.0), while $\mathrm{HgCl}_{3}{ }^{-}$anions are coextracted with $\mathrm{H}^{+}$ions into the membrane at $\mathrm{pH}$ 7.4. The membrane renewal was accomplished by stripping $\mathrm{HgCl}_{3}{ }^{-}$out of the membrane with a base solution of $\mathrm{pH}$ 10.0. Effective stripping of $\mathrm{HgCl}_{3}-$ from the $\mathrm{pH}$ cross-sensitive potentiometric sensor is demonstrated in Fig. 3. As illustrated, the potential response is fully reversible with a good reproducibility of a $0.5 \mathrm{mV}$ standard deviation ( $30 \mathrm{nM}, n=5)$.

\subsection{Application}

The asymmetric membrane based $\mathrm{HgCl}_{3}{ }^{-}$-selective electrode exhibits a high sensitivity and excellent selectivity for the detection of mercury under optimum experimental conditions. The feasibility of the proposed electrode for mercury determination was evaluated by assessing total mercury potentiometrically in the certified reference material of the seawater sample (GBW(E) 080042). Since the concentration of $\mathrm{Cl}^{-}$in the seawater samples is $0.5 \mathrm{M}$, all samples were diluted 1:10 with deionized water before measurement. After dilution, the mercury contents in spiked seawater samples were potentiometrically determined with the proposed membrane

Table 3

Total mercury concentrations determined by the proposed approach in spiked seawater samples. ${ }^{\mathrm{a}}$

\begin{tabular}{lllr}
\hline & Total mercury $(\mu \mathrm{g} / \mathrm{L})$ & Amount found $(\mu \mathrm{g} / \mathrm{L})$ & Recovery $(\%)$ \\
\hline GBW(E) 080042 & 1.0 & $-^{\mathrm{b}}$ & $-{ }^{\mathrm{b}}$ \\
$+20 \mu \mathrm{g} / \mathrm{L} \mathrm{HgCl}_{2}$ & 21.0 & 21.8 & 109 \\
$+40 \mu \mathrm{g} / \mathrm{L} \mathrm{HgCl}_{2}$ & 41.0 & 39.4 & 98 \\
$+50 \mu \mathrm{g} / \mathrm{L} \mathrm{HgCl}_{2}$ & 51.0 & 52.8 & 106 \\
\hline
\end{tabular}

a Average value of three determinations.

b Undetectable. electrode. The results are given in Table 3. It can be seen that the recoveries of seawater samples vary from $98 \%$ to $109 \%$, indicating that the proposed sensor has promising potential for the determination of total mercury contents in marine samples.

\section{Conclusions}

A highly sensitive and selective potentiometric sensor for the determination of mercury anions using lead ionophore IV as anion-selective ionophore and TDMACl as ion exchanger has been described. Combined with the asymmetric membrane rotating ISE configuration, the sensor offers a low detection limit of $4.5 \times 10^{-10} \mathrm{~mol} / \mathrm{L}$ for $\mathrm{HgCl}_{3}-$ in $0.05 \mathrm{M} \mathrm{NaCl}$. It is expected that various metal-chloride complexes at trace levels in $\mathrm{Cl}^{-}$-rich media such as marine and biological environments can be determined by using different anion-selective ionophores.

\section{Acknowledgements}

This work was financially supported by the Instrument Developing Project of the Chinese Academy of Sciences (YZ201161), the National Natural Science Foundation of China (41206087 and 21475148), the National 863 high technology Project of the Ministry of Science and Technology of China (2007AA09Z103), and the Taishan Scholar Program of Shandong Province (TS20081159).

\section{Appendix A. Supplementary data}

Supplementary data associated with this article can be found, in the online version, at http://dx.doi.org/10.1016/j.snb.2014.11.040.

\section{References}

[1] D. Normile, In Minamata, mercury still divides, Science 341 (2013) 1446-1447.

[2] G. Giakisikli, M. Miró, A. Anthemidis, Integrated lab-in-syringe platform incorporating a membraneless gas-liquid separator for automatic cold vapor atomic absorption spectrometry, Anal. Chem. 85 (2013) 8968-8972.

[3] M. Puanngam, P.K. Dasgupta, F. Unob, Dual stage preconcentration of trace aqueous mercury for cold vapor atomic absorption spectrometry, Talanta 99 (2012) 1040-1045.

[4] L. Beaudin, S.C. Johannessen, R.W. Macdonald, Coupling laser ablation and atomic fluorescence spectrophotometry: an example using mercury analysis of small sections of fish scales, Anal. Chem. 82 (2010) 8785-8788.

[5] Z. Liu, Z. Zhu, H. Zheng, S. Hu, Plasma jet desorption atomization-atomic fluorescence spectrometry and its application to mercury speciation by coupling with thin layer chromatography, Anal. Chem. 84 (2012) 10170-10174.

[6] L. D‘Ulivo, L. Yang, Y.L. Feng, Z. Mester, Acid extraction for the determination of methyl mercury in biotissues by isotope dilution gas chromatography inductively coupled plasma-mass spectrometry, Anal. Methods 5 (2013)7127-7131.

[7] S.J. Liu, H.G. Nie, J.H. Jiang, G.L. Shen, R.Q. Yu, Electrochemical sensor for mercury(II) based on conformational switch mediated by interstrand cooperative coordination, Anal. Chem. 81 (2009) 5724-5730.

[8] Z.Q. Zhu, Y.Y. Su, J. Li, D. Li, J. Zhang, S.P. Song, Y. Zhao, G.X. Li, C.H. Fan, Highly sensitive electrochemical sensor for mercury (II) ions by using a mercuryspecific oligonucleotide probe and gold nanoparticle-based amplification, Anal. Chem. 81 (2009) 7660-7666.

[9] E. Bakker, E. Pretsch, Potentiometric sensors for trace-level analysis, Trends Anal. Chem. 24 (2005) 199-207.

[10] J. Bobacka, A. Ivaska, A. Lewenstam, Potentiometric ion sensors, Chem. Rev. 108 (2008) 329-351.

[11] E. Bakker, E. Pretsch, Modern potentiometry, Angew. Chem. Int. Ed. 46 (2007) 5660-5668.

[12] A. Malon, T. Vigassy, E. Bakker, E. Pretsch, Potentiometry at trace levels in confined samples: ion-selective electrodes with sub-femtomole detection limits, J. Am. Chem. Soc. 128 (2006) 8154-8155. 
[13] A. Numnuam, K. Chumbimuni-Torres, Y. Xiang, R. Bash, P. Thavarungkul, P. Kanatharana, E. Pretsch, J. Wang, E. Bakker, Potentiometric detection of DNA hybridization, J. Am. Chem. Soc. 130 (2008) 410-411.

[14] T. Lindfors, J. Szücs, F. Sundfors, R.E. Gyurcsányi, Polyaniline nanoparticle-based solid-contact silicone rubber ion-selective electrodes for ultratrace measurements, Anal. Chem. 82 (2010) 9425-9432.

[15] X.G. Li, H. Feng, M.R. Huang, G.L. Gu, M.G. Moloney, Ultrasensitive Pb(II) potentiometric sensor based on copolyaniline nanoparticles in a plasticizer-free membrane with a long lifetime, Anal. Chem. 84 (2012) 134-140.

[16] M.R. Huang, Y.B. Ding, X.G. Li, Lead-ion potentiometric sensor based on electrically conducting microparticles of sulfonic phenylenediamine copolymer, Analyst 138 (2013) 3820-3829.

[17] M.R. Huang, Y.B. Ding, X.G. Li, Combinatorial screening of potentiometric $\mathrm{Pb}$ (II) sensors from polysulfoaminoanthraquinone solid ionophore, ACS Comb. Sci. 16 (2014) 128-138.

[18] M.R. Huang, X.W. Rao, X.G. Li, Y.B. Ding, Lead ion-selective electrodes based on polyphenylenediamine as unique solid ionophores, Talanta 85 (2011) 1575-1584.

[19] A.R. Fakhari, M.R. Ganjali, M. Shamsipur, PVC-based hexathia-18-crown-6tetraone sensor for mercury(II) ions, Anal. Chem. 69 (1997) 3693-3696.

[20] P. Bühlmann, E. Pretsch, E. Bakker, Carrier-based ion-selective electrodes and bulk optodes. 2. Ionophores for potentiometric and optical sensors, Chem. Rev. 98 (1998) 1593-1687.

[21] H. Khani, M.K. Rofouei, P. Arab, V.K. Gupta, Z. Vafaei, Multi-walled carbon nanotubes-ionic liquid-carbon paste electrode as a super selectivity sensor: application to potentiometric monitoring of mercury ion(II), J. Hazard. Mater. 183 (2010) 402-409.

[22] J. Juarez-Gomez, F. Perez-Garcia, M.T. Ramirez-Silva, A. Rojas-Hernandez, C.A. Galan-Vidal, M.E. Paez-Hernandez, Solid-contact Hg(II)-selective electrode based on a carbon-epoxy composite containing a new dithiophosphate-based ionophore, Talanta 114 (2013) 235-242.

[23] K.J. Powell, P.L. Brown, R.H. Byrne, T. Gajda, G. Hefter, S. Sjöberg. H. Wanner, Chemical speciation of environmentally significant heavy metals with inorganic ligands. Part 1: The $\mathrm{Hg}^{2+}-\mathrm{Cl}^{-}, \mathrm{OH}^{-}, \mathrm{CO}_{3}{ }^{2-}, \mathrm{SO}_{4}{ }^{2-}$, and $\mathrm{PO}_{4}{ }^{3-}$ aqueous systems, Pure Appl. Chem. 77 (2005) 739-800.

[24] Y. Kim, J. Kim, K.N. Kim, S.K. Chang, T.D. Chung, Potentiometric response of a neutral-carrier-based membrane to aqueous mercury in $\mathrm{Cl}^{-}$-rich media, Anal. Sci. 25 (2009) 567-570.

[25] W. Qin, R.N. Liang, X.L. Fu, Q.W. Wang, T.J. Yin, W.J. Song, Trace-level potentiometric detection in the presence of a high electrolyte background, Anal. Chem. 84 (2012) 10509-10513.

[26] R.N. Liang, L.J. Kou, Z.P. Chen, W. Qin, Molecularly imprinted nanoparticles based potentiometric sensor with a nanomolar detection limit, Sens. Actuators B 188 (2013) 972-977.

[27] E. Bakker, Determination of improved selectivity coefficients of polymer membrane ion-selective electrodes by conditioning with a discriminated ion, J. Electrochem. Soc. 143 (1996) L83-L85.

[28] S. Kamaata, A. Bhale, Y. Fukunaga, H. Murata, Copper(II)-selective electrode using thiuram disulfide neutral carriers, Anal Chem 60 (1988) 2464-2467.

[29] K.J. Powell, P.L. Brown, R.H. Byrne, T. Gajda, G. Hefter, S. Sjöberg, H. Wanner, Chemical speciation of $\mathrm{Hg}(\mathrm{II})$ with environmental inorganic ligands, Aust. J. Chem. 57 (2004) 993-1000.

[30] I.H.A. Badr, M.E. Meyerhoff, S.S.M. Hassan, Potentiometric anion selectivity of polymer membranes doped with palladium organophosphine complex, Anal. Chem. 67 (1995) 2613-2618.
[31] D.J. Eisler, R.J. Puddephatt, Tetraphosphinitoresorcinarene complexes: cationic silver(I) and copper(I) halide complexes as mercurate(II) anion receptors, Inorg. Chem. 42 (2003) 8192-8202.

[32] L. Maron, A. Dommergue, C. Ferrari, M. Delacour-Larose, X. Faïn, How elementary mercury reacts in the presence of halogen radicals and/or halogen anions: a DFT investigation, Chem. Eur. J. 14 (2008) 8322-8329.

[33] B.C. Ye, B.C. Yin, Highly sensitive detection of mercury(II) ions by fluorescence polarization enhanced by gold nanoparticles, Angew. Chem. Int. Ed. 47 (2008) 8386-8389.

[34] S. Mathison, E. Bakker, Effect of transmembrane electrolyte diffusion on the detection limit of carrier-based potentiometric ion sensors, Anal. Chem. 70 (1998) 303-309.

[35] W.E. Morf, M. Badertscher, T. Zwickl, N.F. de Rooij, E. Pretsch, Effects of ion transport on the potential response of ionophore-based membrane electrodes: a theoretical approach, J. Phys. Chem. B 103 (1999) 11346-11356.

[36] T. Zwickl, T. Sokalski, E. Pretsch, Steady-state model calculations predicting the influence of key parameters on the lower detection limit and ruggedness of solvent polymeric membrane ion-selective electrodes, Electroanalysis 11 (1999) 673-680.

[37] T. Sokalski, T. Zwickl, E. Bakker, E. Pretsch, Lowering the detection limit of solvent polymeric ion-selective electrodes. 1. Modeling the influence of steadystate ion fluxes, Anal. Chem. 71 (1999) 1204-1209.

[38] T. Sokalski, A. Ceresa, M. Fibbioli, T. Zwickl, E. Bakker, E. Pretsch, Lowering the detection limit of solvent polymeric ion-selective membrane electrodes. 2. Influence of composition of sample and internal electrolyte solution, Anal. Chem. 71 (1999) 1210-1214.

[39] A. Hulanicki, R. Lewandowski, Some properties of ion-selective electrodes based on poly (vinyl chloride) membranes with liquid-ion-exchanger, Chem. Anal. (Warsaw) 19 (1974) 53-60.

[40] M. Maj-Źurawska, T. Sokalski, A. Hulanicki, Interpretation of the selectivity and detection limit of liquid ion-exchanger electrodes, Talanta 35 (1988) 281-286.

[41] S. Mathison, E. Bakker, Renewable pH cross-sensitive potentiometric heparin sensors with incorporated electrically charged H+ ionophores, Anal. Chem. 71 (1999) 4614-4621.

\section{Biographies}

Rongning Liang received his Doctor's degree in 2011 from Yantai Institute of Coastal Zone Research, Chinese Academy of Sciences. He is now an assistant professor at Yantai Institute of Coastal Zone Research. His current research interests are the applications of potentiometric sensors to environmental monitoring.

Qianwen Wang received her Master's degree from Yantai Institute of Coastal Zone Research, Chinese Academy of Sciences in 2012. She is now a laboratory technician at Qingdao Agricultural University. She is mainly engaged in the research of environmental analysis and monitoring.

Wei Qin received his Doctor's degree from Nanjing University in 1998. From 1999 to 2003, he did his postdoctoral research at Swiss Federal Institute of Technology (ETH), University of South Carolina and University of Michigan, respectively. He has been working as Professor at Yantai Institute of Coastal Zone Research since 2006. His research interests are chemical sensors and biosensors for environmental analysis. 